\title{
Pregnancy and Maternity at Workplace, a Qualitative Study to Know the Employers' Perspective
}

\author{
Tazeem Akhtar1, Muhammad Athar Khan² \\ ${ }^{1}$ Department of Community Medicine, University College of Medicine and Dentistry, University of Lahore, Lahore, \\ Pakistan. ${ }^{2}$ Department of Community Medicine, Institute of Public Health, University of Lahore, Lahore, Pakistan.
}

\section{ABSTRACT}

\section{BACKGROUND}

The twentieth century witnessed women expanding the range of possibilities for their gender; by participating as professionals in different fields and by actively dissolving the boundaries of the traditionally held gender roles and they continue to work even during the most crucial phase of their life, that is pregnancy. Discussing the factors related with women's career progress, the negative aspects were found to be domination of men in senior executive positions, discrimination against women, and gender stereotyping. The main objective of this study was to take point of view of employers regarding pregnancy at workplace, their concerns and challenges and how they place themselves in the whole scenario of changing environment for a worker.

\section{METHODS}

A qualitative study design was adopted by conducting semi-structured interviews for which a guideline was developed beforehand. In depth interviews were conducted with the employers at different levels in different organizations of Lahore.

\section{RESULTS}

Classical content analysis of interviews revealed that employers display unfavourable attitude towards the employment of childbearing age group women in the first place and pregnancy at workplace is not a welcoming event at all. All this negative attitude is due to the cost and HR issues raised by the absences and maternity leave of a pregnant worker. There is a great chaos regarding workload shared by the colleagues in pregnant women's absence. For maternity leave, cost of hiring a new person and training are the issues raised by the employers especially in small organizations.

\section{CONCLUSIONS}

There is a great need to give awareness to workers as well as management regarding laws and regulations about maternity at workplace.

\section{KEY WORDS}

Employer, Interviewee, Working Women, Pregnancy
Corresponding Author: Dr. Tazeem Akhtar, Department of Community Medicine, University College of Medicine and Dentistry, University of Lahore, Lahore, Pakistan.

E-mail: tazeemshahbaz@hotmail.com

DOI: 10.14260/jemds/2020/137

Financial or Other Competing Interests: None.

How to Cite This Article:

Akhtar T, Khan MA. Pregnancy and maternity at workplace, a qualitative study to know the employers' perspective. J. Evolution Med. Dent. Sci. 2020;9(09):619624, DOI: $10.14260 / \mathrm{jemds} / 2020 / 137$

Submission 15-11-2019, Peer Review 04-02-2020

Acceptance 11-02-2020,

Published 02-03-2020.

\section{(i)}




\section{BACKGROUND}

In the recent years, women have occupied a considerable number of paid positions in the labour market and continue to work even during periods of pregnancies but even though, women form a large part of the labour force, they are being discriminated against at the work place just due to their unique biological ability to bear children [1]. To curb this, issue the maternity protection and anti-discrimination legislation has taken various steps internationally against the increasing health and safety concerns related to the participation of females in the working sector especially catering to pregnant women. Internationally, women contribution to the work force remains fairly constant at around 52 percent in the two decades from 1990 to 2010. In 2010, Women's share in the labour force remains below 30 percent in Northern Africa and Western Africa; In Southern Asia the rates were below 40 percent. Majority of workers, especially women in those regions are in vulnerable employment being either own account workers or contributing family workers [2]. As far as developed countries are concerned, the ratio of pregnant women in employment is on continuous rise over the past decades since 1970. In United States, women made $46.7 \%$ of labour force in 2001 2003 but have increased to 51 percent in 2015.73 percent of women are employed full time and 27 percent are part time workers. Almost two third of women (62\%) in child bearing age who gave birth in last year were working in labour force in 2008 [3]. First time mothers who worked during their pregnancy reported to be 67 percent, 87 percent of them found to be worked till third trimester and 64 percent worked though out their pregnancies till the end of ninth month. Similarly, in Australia, women make 46 percent of total employees. Out of total employment, women claim 35.7 percent of full time and 69.1 percent of part time jobs.

In order to get the required result of investment on child, pregnant females need to be taken care of. In European countries more than $50 \%$ of the females are employed, so female play a crucial part in economy of the country. And as women are the natural bearer of the next generation it is really important to consider each and every aspect of them [4]. For this many laws have been established by European countries for the privileges of pregnant women at place of work within UK, USA and Canada. As in USA 59\% of women take part in labour force while in UK 70\% of women are a part of labour force. In Canada according to employment insurance act of 1993, 15 days of paid pregnancy leave has been provided. If pregnant women are unable to perform their tasks effectively than they can temporarily transfer their duties to someone else. Secondly it's completely forbidden to fire women from job just because she is expecting [4].

The medical and family leave act of 1993, further ensure an unpaid leave of 12 weeks, without the fear of losing one's job. Pakistani women face many cultural and social obstacles that hinder them from participating in the labour market [5]. These include restrictions on mobility and higher education, lack of moral support by family members and uneven allocation of jobs in almost every sector of the economy etc. Such discrimination limits women from searching for good jobs. Pregnancy is an issue not associated in male dominant society so females especially employed women being the main factor are highly affected by this. But as they are an important part of our economy and no country could flourish without their support both at household level as well as at workforce level [6]. That is why there has been a need to cater all the problems associated with them thereby ensuring a good atmosphere for their excellent productivity. The focus of this research is to highlight all the issues related with women labour force, how to cater them and to decide the most suitable plans to hold up women throughout pregnancy.

As there has been clear need of developing policies and regulations for the physical, mental care of pregnant ladies along with their job security, so the regulating authorities should pay attention toward this issue and bring out the required laws and policies. The present study tried to explore the following research questions-

1. What are the factors, which create a hindrance in fulfilling the rights of pregnant workers in an organization?

2. What is the perspective of employers regarding pregnancy at workplace?

3. How did they cope with the role conflict that possibly emerges with respect to pregnant workers?

\section{METHODS}

\section{Study Design}

A qualitative study design was adopted by conducting semistructured interviews for which a guideline was developed beforehand. In depth interviews were conducted with the employers at different levels in different organizations of Lahore.

\section{Sample \\ The sample size was taken purposively and eight participants were interviewed. The interviewees were chosen on the basis of their role in hiring, making general rules and policies and in implementation of those policies. In this study, only those employers were interviewed, who have dealt with at least one case of pregnant worker in last year. Among the participants, two were owners of small organizations, three of them were CEOs of national or international companies and three of them were executive managers of organizations.}

\section{Tool}

Semi structured interviews with some guidelines were used as a tool. The questions asked were broadly regarding pregnancy at workplace, their role, adjustments made and experiences of their co-workers. A guideline for this was made beforehand. Although, some adaptations were made according to the responses of participants but due to similarity of experiences, no difficulty was observed in following the interview guidelines. Some of the questions asked were: What do you think about working of women during pregnancy especially till end of pregnancy? How do you facilitate your pregnant workers? What is your organization's maternity leave policy? What is your view regarding discrimination due to pregnancy and what is the organization policy regarding this?

\section{Procedure}

Participants were approached in their offices and a briefing regarding study, their confidentiality, anonymity and right to quit at any time during interview was given. Informed 
consent was taken. Each interview took almost an hour. Written notes were taken during interview along with recording. Later on, interviews were transcribed and findings were matched with written notes for better analysis.

\section{Data Analysis}

Interpretative phenomenological analysis was used to analyse data and following steps were followed-

1. After reading each participants interview, emergent themes were developed.

2. Then sub ordinate themes were developed by noting similarities among responses

3. Major themes emerged from sub ordinate themes by taking into account of their similar meaning

4. In last step, analysis of these done.

\section{RESULTS}

\begin{tabular}{|c|c|c|}
\hline Serial No. & Level & Code for Finding \\
\hline \multirow{2}{*}{1} & Owners (Small organizations) & Owner 1 \\
2 & CEO's (National or multinational & Owner 2 \\
2 & organization) & CEO 1 \\
3 & & CEO 3 \\
& Executive Managers & Manager 1 \\
& & Manager 2 \\
& & Manager 3 \\
\hline \multicolumn{2}{|c|}{ Table 1. Participants Who Were Interviewed in This Study } \\
\hline
\end{tabular}

Analysis of data revealed that perspective of the employers can be summarized in three levels which is depicted as a model in figure 1.

\section{Employer's Perceptions Regarding Pregnancy at Workplace}

The participants showed a varied behaviour and attitude regarding the pregnancy at workplace. This can begin at one end with positive attitude towards them and on the other end, some showed hostility towards workers who are either pregnant or mothers. The main factors contributing to this resentful attitude were the obligations and responsibilities that were placed on the employers due to pregnant workers. In this wide range of views, it can be seen easily that participants who had shown positive attitude towards pregnancy and maternity at workplace, at some point expressed their concern regarding difficulties, which small organizations have to face in handling this situation. Small organizations, no doubt, see pregnancy at workplace as a potential problem that they have to handle, not a welcoming situation [7]. For small organizations, the hostility factors against pregnancy and maternity at work place come from the fact that they, generally, don't support labour law and has resentful attitude towards maternity act specially. The reason behind this attitude seems to be paid leaves, which they think is burden on an organization. Along with these views, when same question was placed in front of two other participants who were employee of multinational organizations, were of the opposite view but they also saw sharing of burden of pregnancy and maternity somewhat hard and of the view that legislation regarding this is in favour of employee and is not in favour of small organizations. They not only expressed their agreements on working of women but also providing them with the environment conducive to their working while pregnant. When same thing was discussed with the executive managers who were responsible for implementation of policies formulated at higher levels, they showed some reservations [8].

"We cannot set aside other issues when we talk about pregnancy at workplace. I mean, It's good for the worker but for the employer that will be another burden. I mean giving paid maternity leave and then handling the replacement for that period. It's really hard for a company as small as mine." Owner 1. "Yes, if you are a small organization, then to replace the person for a certain period, to give extra money, to bear maternity charges along with paid leaves, you feel that you are at losing end." Owner 2. "The protection in law for employee is more than for employers but honestly speaking, apart from multinational, very few of them follow this law." "To say they should work during pregnancy will not be enough. Actually, measures are needed to encourage them to come for work during this stage of their life." "As far as, I know, by law employers are at losing end especially of smaller organizations. All the responsibilities lie within the employers. Not a single law putting any obligation on pregnant worker for working full time, hard or returning back to same company etc.". "They should be hired even during their pregnancy and should be given insurance regarding their job even after delivery" gave another view of this. "As far as their right to antenatal appointments are concerned, I can give time off but regarding 100 percent's payments, I don't think it's feasible or manageable for my institute." "They should be hired but most of them became problematic at the end and to handle them at work makes the environment a bit lousy." "Yes, I think, they should work and be facilitated by the management at all stages of pregnancy, as they are nurturing our future." "To be good employer in this competitive world, you have to respect the legislation but to make option viable, we as an organization have right to make some amendments according to our own convenience. Actually to afford one maternity in a year is oaky but what about 2, 3 or even 4 in a year. It's really difficult to manage work load, replacements and above all payments ".

At the end, it was very interesting to note the views of female employers who owned a small business or was heading some institution; they could see the pregnancy and maternity at workplace from both perspectives, as an employee and as an employer as well [9]. As an employee, they were of the view that increased rights and supportive attitude should be offered to all the pregnancies at workplace but as an employer, they shared the same concerns of over burdening of the smaller organizations

\section{Issues and Concerns Regarding Pregnancy at Workplace}

When explored issues and concerns of participants about pregnancy and maternity at workplace, it was found that they face same types of issues and their concerns were consistent. The different questions asked and themes and subthemes, which emerged, were: -

\section{Hiring of Pregnant Workers}

The issue that was directly concerned with pregnant workers and all other women of childbearing age is their recruitment, as mentioned by some of the respondents. All other, although denied doing this but confessed that they had seen this 
practice many times even in their own organizations when a male worker was given preference over a female worker due to this issue [3,4,5]. "I think, when we over emphasize the rights of being paid maternity leave and medical expenses of pregnant workers and mothers at work place, we should not forget that we are placing them in a situation where employers will hesitate to hire them in them the first place and they have to face discrimination at hiring level in this situation. Yes, they can do so to save themselves from future problems." "They actually wanted to hire a male worker to replace a pregnant worker while she was going on maternity leave to save themselves from future hassles."

\section{Maternity Leave and Cost}

All the interviewees raised many concerns regarding this issue but the most striking one was paid maternity leaves and its cost itself and the difficulties a firm face due to absence of a particular employee. Respondents reported that at many times, the main concerns were not only paid maternity leave and medical expenses which were obvious and well calculated ahead but the hidden costs and expenses which were not quantified and included cost of recruitment and training to the replacement person. His salary and benefits and time factor were other factors [10,11]. "Sometimes, it's a more a time and training issue rather than finances." "Oh, It's a mess ... a real mess. When you have trained a person for a particular job and in our full running season, she had to go on leaves for three months. It's not only a disaster for the company in terms of hiring a new person on locum but also we had to bear the loss in terms of losing our customers and so many more losses and still there was not surety that she would return back after delivery and availing the so called maternity leave."

\section{Re-Joining the Job}

It was found to be more complicated for the small organizations, where all the above issues seemed to be compounded by the doubts about re-joining of female workers after delivery. The uncertainty related with rejoining back of female workers after their delivery and maternity leave found to be huge problem for the employers. In many instances, employers reported that their employee had said that they would join but did showed up after leaves Female employers were sympathetic about this but male employers were clearly not ready to accept the situation. This issue was noted more upsetting for small employers [6,7]. "Mostly the female workers don't return to their jobs after delivery and we have to hire another person for that job. I will not lie, but we usually try although in softer way that she can give us any clue about her return to job but don't get any many times." "One of my employee said, she will come back after leaves and we planned accordingly but at the nick of time she changed her mind and stayed at home. It was really a upset and we had to face many consequences. I mean. That was a real emergency at that time to handle the situation." A manager [9]. "I know, it's difficult to decide especially when you are pregnant first time whether to join or not but what about other side. What should we do/ can we leave the vacancy open forever. Come on we have to run our business.' "It's really difficult to arrange replacements for three months and when somebody did not show up after leave on expected date, the process started again. It's wastage of time, training and finances. Very difficult for a small institute where human resource matters a lot.' An employer

\section{Time-Off during Pregnancy}

Many interviewees shared their concerns about time-off taken by pregnant workers for antenatal visits or for any medical condition. They stated that many of their employees had taken extra advantage of this facility in the form of longer time off than required or more time offs than needed actually Women employers were of supportive view regarding time off for antenatal or medical visits as they themselves had passed through this experience [3,4]. "How could one know whether time off is for antenatal or any medical appointment or for anything else? Once, I found my employee doing shopping while she was actually availing that time off. It looks so indecent to ask for some proof of medical appointments." A manager reported. "Actually pregnancy is a whole new experience for a woman and the organizations and employers should support it in such way to make it memorable for her. It will definitely add value to her work and pay back to company in the long run."

\begin{tabular}{|c|c|}
\hline Themes & Aspects \\
\hline $\begin{array}{l}\text { Views regarding pregnancy at } \\
\text { workplace }\end{array}$ & $\begin{array}{ll} & \text { Viewed as a problem } \\
- & \text { Unwelcoming but un escapable issue } \\
- & \text { Maternity law favours employee } \\
\text { - } & \text { Other employee sees it as a burden } \\
\end{array}$ \\
\hline \multicolumn{2}{|c|}{ Issues and Concerns Regarding Pregnancy at Workplace } \\
\hline Hiring of pregnant workers & $\begin{array}{ll}- & \text { Hesitation in hiring } \\
- & \text { Preference to male workers } \\
\end{array}$ \\
\hline Maternity leave policy & $\begin{array}{ll}\text { - } & \text { Clear-cut in line with government } \\
\text { - } & \text { Hidden costs and expenses } \\
\text { - } & \text { Time and training issues } \\
& \text { Difficult to find replacements }\end{array}$ \\
\hline Re-joining the job & $\begin{array}{ll} & \text { Uncertainty on the part of employers } \\
\text { - } & \text { Mostly do not join after delivery }\end{array}$ \\
\hline Time off during pregnancy & - $\quad$ Concerns of taking extra advantage \\
\hline Issues with other staff & $\begin{array}{ll} & \text { Fifty percent non-supportive even } \\
& \text { resentful } \\
\text { - } & \text { Fifty percent supportive } \\
\end{array}$ \\
\hline \multicolumn{2}{|c|}{ Table 2. In-Depth Interview Themes } \\
\hline
\end{tabular}

\section{Issues with Other Staff}

When asked about any issue or concerns of other staff members regarding pregnancy at workplace, almost fifty percent of participants reported about the difficult to handle attitudes and behaviours of their other staff members. One to two employers even reported resentful behaviour of staff towards pregnant colleagues because they had to do extra work or some assignment due to her absence. Almost half of the employers seemed to be aright and happy with the attitude their staff members had with their pregnant colleagues and that was mainly a supportive one, but this type of attitude was mainly reported by employers working in multinational or big companies [11]. "They are happy if she is not demanding extra medical leaves or any other support but the moment, she demands for some favour like flexi hours or breaks etc., you hear comments like "pregnancy is a normal process" "Why treat her differently when paid equally" or something in a humorous way 'is there anything like this for us too." Or even like" such a lucky lady. No work but full pay." Manager reported "Sometimes, it's really hard to handle others as, they have to do extra work and give her cover....... I have to think and act diplomatically in these situations." Another manager stated. "I think my colleagues had no issue with my pregnancy and I did not witness any 
such thing from their side for any other employee as well. They are so supportive that they sometimes went out of way to give them comfortable environment. We recently had an example and she was really happy with their attitude and caring behaviour. I know that still they are in contact with her and waiting for some good news."

\section{DISCUSSION}

The main objective of conducting this research was to explore and understand views of employers regarding pregnancy at workplace, to share their experience and to know their concerns and issues they face while having a pregnant employee at their workplace [6]. Our research tried to take an insight right from beginning of pregnancy at workplace to going for a maternity leaves and then inducting back the employee after childbirth and postnatal period. As the participants were belonged to both small and large organizations and female employers were also included in interviews, the viewpoint gained was quite elaborate and was self-explanatory [12].

General attitudes regarding pregnancy at workplace was not found to be encouraging and welcoming rather it was seen as a problem to handle by small organizations where persons to replace the employee are difficult to find and hire. The employer type and size of an organization was found as main factors in negative treatment faced by pregnant women. It was highest in retail companies. It was equally noticed on both ends like managers and lower staff workers. Studies showed more negative attitudes faced by pregnant women who were first time pregnant, having high income before pregnancy or have a short tenure in companies [13].

Another feeling shared by participants were that they think that maternity leave policy is more friendly to the employee than employers and being small institutes, they were unable to cope with the emergencies or personal favours like these. Small organizations with less number of employees faced more difficulties in handling pregnancy at workplace, as they mentioned about problems they faced in arranging for substitutes for leaves and managing workloads by other staff members. The issues, which were shared by most employers, were making arrangements of substitutes, their training and most of all the uncertainty, which is related, with the returning of the workingwomen after delivery or maternity leaves [14].

Managing paid maternity leaves for 12 weeks were also seen as a problem for smaller institutes and many of them were not following the statutory policies established by government in this regard. Studies have shown that more awareness about the regulations and policies regarding maternity leave resulted in fewer problems for the pregnant workers. Similarly, workingwomen of private sector faced more negative treatment as compared to public sector. No one mentioned about ant risk management for the pregnant workers at all. Although legislation is there but to act upon these legislations was seen far fetch dream [15]. Almost all the employers showed some hesitation regarding hiring of women in childbearing age. Even the female employers were of the view that they had seen this discrimination but unable to do something. Similar finding was reported in a study where workingwomen were refused for flexible timing and made redundant due to their pregnancy. Another study supported this finding with the reports of family unfriendly policies of smaller organizations and their effects on the pregnant women especially.

\section{CONCLUSIONS}

Employers have their own views regarding this issue. They have unfavourable attitude towards the employment of childbearing age group women in the first place and pregnancy at workplace is not a welcoming event at all. All this negative attitude is due to the cost and HR issues raised by the absences and maternity leave of a pregnant worker. There is a great chaos regarding workload shared by the colleagues in pregnant women's absence due to sick leave or maternity leave. For maternity leave, cost of hiring a new person, training her and time cost along with payment for maternity and medical leave are the issues raised by the employers especially in small organizations. Firstly, there is a great need to increase the understanding of the employers regarding the unique phenomenon of pregnancy. They should be given ample knowledge about balance between work and personal life of an employee and how to handle the sensitive situations like a pregnancy in a morally and ethically correct way. Supervisors should be given training regarding maternity handling through some developmental programs. Secondly, General discussions with employees regarding maternity policies and moral and ethical aspects need to be discussed by the employers in a friendly way. It is equally important for the organizations to value the different workers in order to maintain diversity of experiences and also to promote commitment and willingness to return to job.

\section{REFERENCES}

[1] Gatrell C. Managing the maternal body: a comprehensive review and transdisciplinary analysis. International Journal of Management Reviews 2011;13(1):97-112.

[2] Heslehurst N, Moore H, Rankin J, et al. How can maternity services be developed to effectively address maternal obesity? A qualitative study. Midwifery 2011;27(5):e170-e7.

[3] Kessler RC, Barber C, Birnbaum HG, et al. Depression in the workplace: effects on short-term disability: Could treating workers' depression help employers to save money on disability? These results are encouraging. Health Affairs 1999;18(5):163-71.

[4] Shearn J, Todd S. Maternal employment and family responsibilities: the perspectives of mothers of children with intellectual disabilities. Journal of Applied Research in Intellectual Disabilities 2000;13(3):109-31.

[5] Furber CM, McGowan L. A qualitative study of the experiences of women who are obese and pregnant in the UK. Midwifery 2011;27(4):437-44.

[6] Sirimi N, Goulis DG. Obesity in pregnancy. Hormones (Athens) 2010;9(4):299-306. 
[7] Stumbitz B, Lewis S, Kyei AA, et al. Maternity protection in formal and informal economy workplaces: The case of Ghana. World Development 2018;110:373-84.

[8] Halley MC, Rustagi AS, Torres JS, et al. Physician mothers' experience of workplace discrimination: a qualitative analysis. BMJ 2018;363:k4926.

[9] Akhter S, Rutherford S, Chu C. What makes pregnant workers sick: why, when, where and how? An exploratory study in the ready-made garment industry in Bangladesh. Reproductive Health 2017;14(1):142.

[10] Gashaw BT, Magnus JH, Schei B, et al. Community Stakeholders' perspectives on intimate partner violence during pregnancy-a qualitative study from Ethiopia. International Journal of Environmental Research and Public Health 2019;16(23). pii: E4694.

[11] Firoz T, Vidler M, Makanga PT, et al. CLIP Working Group. Community perspectives on the determinants of maternal health in rural southern Mozambique: a qualitative study. Reproductive Health 2016;13(Suppl 2):112.
[12] Franks WLM, Crozier KE, Penhale BLM. Women's mental health during pregnancy: a participatory qualitative study. Women and Birth 2017;30(4):e179-e87.

[13] Selboe ST, Skogås AK. Working fulltime throughout pregnancy-the Norwegian women's perspectives. A qualitative approach. Midwifery 2017;50:193-200.

[14] Lauer EA, Armenti K, Henning M, et al. Identifying barriers and supports to breastfeeding in the workplace experienced by mothers in the new hampshire special supplemental nutrition program for women, infants, and children utilizing the total worker health framework. International Journal of Environmental Research and Public Health 2019;16(4). pii: E529.

[15] Glenn EN, Chang G, Forcey LR. Mothering: ideology, experience and agency. $1^{\text {st }}$ edn. New York: Routledge Publisher 2016. 